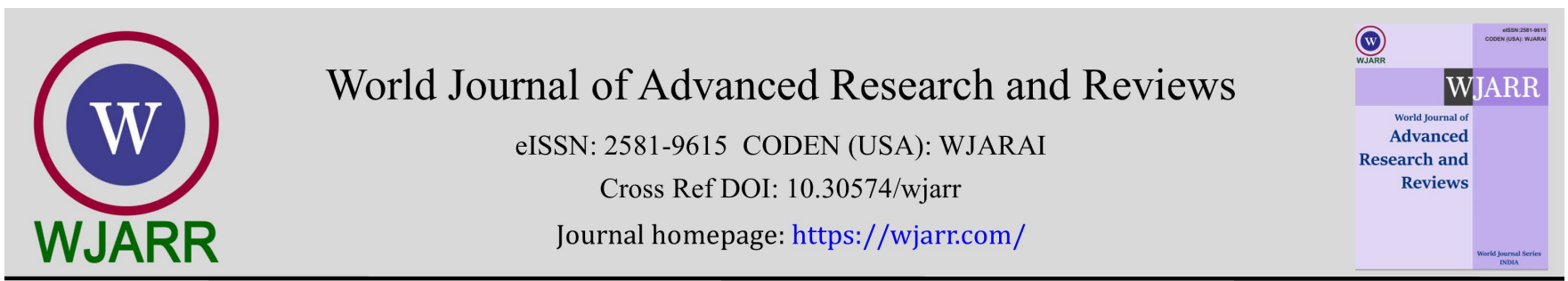

(LETTER TO EDITOR)

\title{
The latest covid-19 impact on the neurosurgery resident admission and training in Morocco
}

\author{
Yao Christian Hugues DOKPONOU * \\ Department of Neurosurgery, Military teaching hospital, Mohammed V University, Rabat, Morocco.
}

World Journal of Advanced Research and Reviews, 2021, 12(03), 155-157

Publication history: Received on 05 November 2021; revised on 06 December 2021; accepted on 08 December 2021

Article DOI: https://doi.org/10.30574/wjarr.2021.12.3.0630

\begin{abstract}
The Kingdom of Morocco is also affected by the COVID-19 in all filed. The coronavirus shutdown has been a great challenge for health policymakers, the citizens, and those traveling down for various reasons. Among them, there are undergraduate students, physicians seeking postgraduate education...etc. Some were lucky enough to start their courses online, pending the time to come to Morocco for continuing their studies. But unfortunately, this was not the case for the potential neurosurgical residents that were already accepted, and some were even holding scholarships but were unable to join their training centers. Meanwhile, a substantial effort has been made to feel the tremendous lack of neurosurgeons in Sub-Saharan Africa by quality massive education and training of neurosurgeons from those countries. Thus, these consequences of the COVID-19 shutdown are a dropping stone in a quiet lack, delaying the important project of the WFNS and others to fill up this gap. At the same time, it is worth thinking about the innovative model of neurosurgical education and training for the new generation of Sub-Saharan African neurosurgeons.
\end{abstract}

Keywords: Neurosurgery education: COVID-19 impact: Morocco: Sub-Saharan Africa.

\section{Introduction}

The World Health Organization recommended a ratio of one neurosurgeon for one hundred thousand population (1: 100 000). According to Prof. El Khamlichi's [1] report, 79 neurosurgeons in Africa in 1998 made a ratio of one neurosurgeon to between 10 to 20 million populations in some African countries. In 2016, this was increased to 369 neurosurgeons, about one neurosurgeon for two million inhabitants. Many events and timely decision-making have been sorted out to reach this exceptional result. As a result, many neurosurgical educational funds/grants came up to support this project: Moroccan Agency for International Cooperation, WFNS Foundation, Africa100-Project...etc. Confirming that only quality and massive training of young neurosurgeons can help to fill this historical gap. All these events were coming into reality and everything was falling into place without foreseeing a possible upcoming worldwide pandemic, the COVID-19. These changes can either delay or temporarily cancel the admission for residency and sometimes demand changes in traditional residency training. This letter highlights the admission procedure to the neurosurgery training program in Morocco for sub-Saharan African aspiring neurosurgeons and the key lessons learned from the Coronavirus pandemic for the potential applicant to the neurosurgical residency program Morocco in 20202021.

\section{Application procedure for neurosurgery residency in Morocco}

To get access to neurosurgical education and training in the kingdom of Morocco, you need to be a medical doctor (MD) or equivalent. The foreign-trained medical doctors should be a citizen of a country where there are $<1$ neurosurgeon

\footnotetext{
* Corresponding author: Yao Christian Hugues DOKPONOU

Department of Neurosurgery, Military teaching hospital, Mohammed V University, Rabat, Morocco.
}

Copyright (C) 2021 Author(s) retain the copyright of this article. This article is published under the terms of the Creative Commons Attribution Liscense 4.0. 
per 1 million inhabitants; commit to returning to native country; recommendation by university authorities in the native country by a Head of Department, Dean or the Medical Director; submit application documents (letter(s) of recommendation, application letter with date of beginning and duration of training, curriculum vitae, copy of the MD diploma or a completion certificate issued by the Faculty of Medicine, and personal photo) [2]. After submitting this application through the Moroccan Agency for International Cooperation, the applicant will wait for the decision from the faculty of medicine and pharmacy of one of the nine (9) training programs to which he submitted his application. The trainees are informed in various ways but mainly by the homeland office of foreign affairs. Then they will come over to the kingdom of Morocco to start the residency training in neurosurgery following their enrollment at the university.

\section{Coronavirus shutdown and neurosurgery residency admission and training}

They have not been a big deal coming to the kingdom of Morocco to start a neurosurgery residency program until the year 2020 with the Covid-19 pandemic shutdown. The World Health Organization officially recognized coronavirus disease 2019 (COVID-19) as a pandemic in mid-March 2020 [3]. COVID-19 pandemic has influenced all aspects of societies, with healthcare being the most affected field. All specialties, including neurosurgery, are involved [4]. As if these were not enough, the subsequent shutdown will unable all accepted undergraduate and post-graduate students to enter the kingdom of Morocco for the academic year 2020-2021. This situation was the same in some other parts of the world. For example, due to the lockdowns in the United States, the U.S. Citizenship and Immigration Services suspended premium processing of $\mathrm{H} 1$-B visas, which would have significantly impacted incoming International Medical Graduates (IMG) residents [5]. An online course has been a solution for most programs that welcome students in Moroccan public universities, but that was not the case for neurosurgery residents. They were informed on the $24^{\text {th }}$ of December 2020, by an open letter sent to the ministry of foreign affairs of each country that due to this rapidly expanding covid-19 pandemic, they will not be able to travel to the kingdom of Morocco and therefore their acceptance for neurosurgery residency as well as scholarship granted will be on standby. This was terrible news for the young aspiring neurosurgeons that were very enthusiastic and overwhelmed to come over and start their residency. On the other hand, this is slowing back all those efforts that have been put into place to continually feel the gap of rarefication of neurosurgeons, mainly in Sub-Saharan African countries. For the main time, only the national residents and those present in the country were able to get into neurosurgery education and training. Thus, others could not travel down, thus, stay back home and wait until the health care authorities confirm a date according to how well the COVID-19 pandemic is handled. In July 2020, Bambakidis and Tomei [6] have described in their editorial how the COVID-19 become a significant concern for their ability to continuing neurosurgical education and supervised the trainees that were involved in the COVID-19 patient care. The Accreditation Council for Graduate Medical Education (ACGME) reiterated that residents who are managing suspected or confirmed COVID-19 cases should have adequate supervision by faculty who are trained in such protocols, which may impact the availability of supervision. Department of Neurosurgery was disrupted and challenged in many ways, requiring adaptations in clinical operations, workforce management, and education. In fact, all neurosurgery departments worldwide have been forced to restructure their training programs because of the COVID-19 pandemic.

\section{Impact on the WFNS objectives and neurosurgery training}

Now that the era of one and only one specialist in a field for a whole country without training any other specialist for his whole carrier has passed, the young generation of neurosurgeons in all Sub-Saharan African countries should be able to set up a training program for neurosurgical education for training the future generation of the neurosurgeon in their homeland. There are many ways to go about this at the beginning. For instance, the resident can be trained for the first 3 years in their homeland training program based on a specific training and learning curve and then be sent into another program (in one of the Moroccan neurosurgery training program) to further their training and come back home to round up their neurosurgical education. Pandemics like COVID-19 will not disturb the training course nor the learning curve when this kind of setting will be a reality in Sub-Saharan countries. Therefore the enormous gap of the neurosurgery workforce will continually be filled toward the WHO gold standard.

\section{Conclusion}

The Sub-Saharan African neurosurgeons should have the courage to draw a training program in their country for neurosurgical education and training of young neurosurgeons. At least, giving them the basics and then allowing them to get into more experienced programs around the globe for perfection is already a good beginning. Pandemics like COVID-19 may disturb the whole training system but will definitely not interrupt the admission of new resident. Following the actual statistics of available neurosurgeons, each Sub-Saharan African country should be able to have its own neurosurgery training program before the year 2030. 


\section{References}

[1] A El Khamlichi. Emerging Neurosurgery in Africa.

[2] Kanmounye US, Zolo Y, Tsopmene MRD, Nguembu S, Ndajiwo AB, Abdifatah K, et al. Understanding the motivations, needs, and challenges faced by aspiring neurosurgeons in Africa: an E-survey. British Journal of Neurosurgery. 22 Dec 2020; 1-6.

[3] Pannullo SC, Guadix SW, Souweidane MM, Juthani RG, Baaj AA, Dupree T, et al. COVID-19: A Time Like No Other in (the Department of) Neurological Surgery. World Neurosurgery. Apr 2021; 148: 256-62.

[4] Meybodi KT, Habibi Z, Nejat F. The effects of COVID-19 pandemic on pediatric neurosurgery practice and training in a developing country. Childs Nerv Syst. Apr 2021; 37(4): 1313-7.

[5] Lu VM, Menendez I, Levi AD, Komotar RJ. Letter to the Editor: Lessons to Learn from the Coronavirus Disease 2019 (COVID-19) Pandemic for International Medical Graduate Applicants and United States Neurosurgery Residency Programs. World neurosurgery. 2020; 141: 571.

[6] Bambakidis NC, Tomei KL. Editorial. Impact of COVID-19 on neurosurgery resident training and education. J Neurosurg. 17 Apr 2020; $1-2$.

\section{Author's short biography}

Dr. Dokponou Hugues is a major of Benin Armed Forces, had worked with the United
Nations as a Deputy Chief Medical Officer; currently undergoing postgraduate training in
neurosurgery at the Mohammed V Military Teaching Hospital of Rabat in Morocco. He is a
peer reviewer for many outstanding international journals and an Associate Editor at the
Pan African Medical Journal. In addition, he has published many scientific papers and co-
authored different reviews in his field.

